\title{
Editorial Letter for the Special Issue on Data Quality in Databases and Information Systems
}

The birth of the inaugural issue of the ACM Journal of Data and Information Quality (JDIQ) marked an important calling to both students and fellow journeymen for sharing, cultivating, and improving research and practice in data and information quality. Through open professional exchange, we hope to have a positive impact on society in general, beyond our native organizations and the immediate field of research and practice.

We appreciate our guest editors, Professors Felix Naumann and Louiqu Rashid, for their time and devotion that made this special issue possible. We also want to acknowledge the guest associate editors and reviewers who worked so hard, often through multiple revisions, to guarantee the high quality of this issue. We are excited to share with you the fruits of those labors.

Computing continues to become increasingly ubiquitous, distributed, and involved with complex multimedia. The source, various qualities of data, and intermediary processes involved in data are not necessarily known or easily traceable throughout the value chain of data and information flow. The articles in this special issue provide unique solutions by identifying those qualities of data which are important prerequisites for devising further information processing and retrieval processes such as data mining and queries that deliver added value to data consumers.

We are pleased to announce that, for a limited time, ACM is making all the articles of the inaugural issue of JDIQ available for free from the ACM Digital Library. The Table of Contents for the inaugural issue, with access to all the articles, is at http://portal.acm.org/toc.cfm?id=1515693. We hope that you will take advantage of this offer, not only to read (or reread) the articles in the issue, but also to share this gift with your colleagues.

We continue to welcome manuscripts with innovative research questions, rigorous use of research methods, and relevant implications of the research findings in future research and practice. While JDIQ welcomes articles from multidisciplinary perspectives, we will highlight articles in special issues that demonstrate research results grounded on selected theoretical perspectives, research methods, industries, or focused problem areas.

Looking forward, we plan to showcase research dealing with the data quality challenges of healthcare services and systems. A copy of the Call for Papers

(c) 2009 ACM 1936-1955/2009/09-ART6 \$10.00. DOI 10.1145/1577840.1577841.

http://doi.acm.org/10.1145/1577840.1577841.

ACM Journal of Data and Information Quality, Vol. 1, No. 2, Article 6, Pub. date: September 2009. 


\section{6: $2 \quad$ S. E. Madnick and Y. W. Lee}

for that special issue is included at the end of this issue. We welcome diverse perspectives and research methods for this future special issue. In addition, we encourage prospective special issue guest editors to discuss with us their own proposals on fresh ideas to other topics.

Stuart E. Madnick (smadnick@mit.edu) and

Yang W. Lee (ylee@mit.edu, y.lee@neu.edu) http://jdiq.acm.org Editors-in-Chief 